\title{
STUDIES OF CHELATION ION-EXCHANGE PROPERTIES OF TERPOLYMER RESIN DERIVED FROM 8-HYDROXYQUINOLINE AND DITHIOOXAMIDE
}

\author{
W. B. Gurnule \\ Department of Chemistry, Kamla Nehru College, Sakkardara, Nagpur 440024, \\ Maharashtra, India. \\ E-mail: wbgurnule@yahoo.co.in, nwgurnule@gmail.com
}

\begin{abstract}
Terpolymer have been synthesized by the condensation of 8-hydroxyquinoline (8-HQ) and dithiooxamide (D) with formaldehyde (F) in the presence of acid catalysts using varying molar proportions of the reactants. Compositions of the terpolymers have been determined by elemental analysis. The number average molecular weights $(\overline{\mathrm{M}} \mathrm{n})$ have been determined by conductometric titration in non-aqueous medium. Intrinsic viscosities of the solutions of the terpolymers have been determined in dimethyl formamide. Thermal behaviour of each terpolymer has also been studied by thermogravimetric analysis (TGA). The terpolymer have been characterized by studying their Uv, IR, NMR spectra and electrical conductivities.
\end{abstract}

Keywords : Absorption, Degree of polymerization (DP), ion exchangers, metal-polymer complex, resins, selectivity.

\section{INTRODUCTION}

The main objective of the most studies on chelating resins, is preparation of insoluble functionalized polymers which can provide more flexible working conditions together with good stability and high capacity for certain metal ions [1-3]. Salicylic acid has been used extensively as an analytical reagent in the determination of metal ions due to its chelating property. The polymeric resin from salicylic acid and formaldehyde was derived by DeGeiso et al. [4] in 1962. They have studied the ion-exchange capacity and selectivity of salicylic acidformaldehyde copolymer with $\mathrm{Fe} 3+$ and $\mathrm{UO} 22+$ ions as a function of $\mathrm{pH}$. Patel et al. $[5,6]$ have prepared the terpolymer of salicylic acid/p-hydroxy 
benzoic acid and thiourea with trioxane in the presence of acid catalyst with different molar proportions of monomers. Kapadia et al. [7,8,9] prepared ionexchange resins from various phenolic derivatives like salicylic acid, gallic acid, $\beta$-resorcylic acid, anthranilic acid, 8hydroxyquinoline, and hydroquinone using DMF as solvent. They have studied their anion as well as cation-exchange properties towards various metal ions.

The present paper has been described the development of a novel ion-exchanger resin process suitable for the desalination of waste water which is high in $\mathrm{Fe}$ (III), $\mathrm{Ni}$ (II) and $\mathrm{Cu}$ (II) ions, to meet effluent discharge specifications. Ion Exchange column of 8-HQDF copolymer resin can be used for removal of the iron, nickel and copper metal ions as well as suspended solids in waste water. It can also be used in the removal of iron from boiler water in industries [10]. The resin can also be used for the removal of iron and zinc from brass. There are many useful reports on ion-exchange separation methods in chemical processes [11].

The basic requirements, which are essential for any polymeric material to be useful as an ion-exchange resins are: a) It must be sufficiently hydrophilic to permit diffusion of ions through the structure at a finite and usable rate. b) It must contain sufficient number of accessible ion-exchangeable groups which do not undergo degradation during use, and c) The swollen material must be denser than water.

So far no resin based on 8-hydroxyquinoline-dithiooxamidefromaldehyde in DMF media has been synthesized for the quantitative separation of transition and post-transition metal ions. As industrial effluents are often rich in transition metal ions, removal of these metals is an important task for industries. Therefore, we have studied the use of ion-exchanger for the removal and separation of heavy trace metal ions. 


\section{EXPERIMENTAL}

\section{Preparation of 8-HQDF terpolymer resin}

A mixture of 8-hydroxyquinoline [1.45g, $0.1 \mathrm{~mol}]$, dithioxamide [1.20 g, $0.1 \mathrm{~mol}]$ and formaldehyde $[7.50 \mathrm{ml}$ of $37 \%$ solution, $0.2 \mathrm{~mol}$ ] in the presence of $2 \mathrm{M}$ hydrochloric acid $(200 \mathrm{ml})$ was heated in an oil bath at $120^{\circ} \mathrm{C} \pm 2^{\circ} \mathrm{C}$ for $5 \mathrm{~h}$ with occasional shaking. The separated resinous product (8-HQDF) was washed with hot water to remove unreacted monomers. The resin was purified by dissolution in $8 \% \mathrm{NaOH}$ and reprecipitated by dropwise addition of $1: 1(\mathrm{v} / \mathrm{v})$ $\mathrm{HCl} /$ water with constant stirring. The precipitated resin product was filtered off, washed with hot water until it was free from chloride ions. The purified terpolymer resins were finally ground well to pass through a 300 mesh size sieve and kept in vacuum over silica gel. The yield of these terpolymer resins were found to be $73-88 \%$.

\section{Ion-exchange properties}

The ion-exchange properties of the 8-HQDF copolymer resins were determined by the batch equilibrium method [12]. The ion exchange properties of all the four resins have been studied. However, only the data for the 8-HQDF copolymer resin has been presented in this paper.

\section{Determination of metal uptake in the presence of various electrolytes and different concentration}

The copolymer sample (25 mg) was suspended in an electrolyte solution $(25 \mathrm{ml})$ of known concentration. The $\mathrm{pH}$ of the suspension was adjusted to the required value by using either $0.1 \mathrm{M} \mathrm{HNO}_{3}$ or $0.1 \mathrm{M} \mathrm{NaOH}$. The suspension was stirred for $24 \mathrm{hrs}$ at $30^{\circ} \mathrm{C}$. To this suspension $2 \mathrm{ml}$ of $0.1 \mathrm{M}$ solution of the metal ion was added and the $\mathrm{pH}$ was adjusted to the required value. The mixture was again stirred at $30^{\circ} \mathrm{C}$ for $24 \mathrm{hrs}$. The polymer was then filtered off and washed with distilled water. The filtrate and the washing were collected and then the amount of metal ion was estimated by titrating against standard EDTA (ethylene diamine tetra-acetic acid) at the same $\mathrm{pH}$ (experimental reading). The same titration has been carried out without polymer (blank reading). The amount of metal ion uptake of the polymer was calculated from the difference 
between a blank experiment without polymer and the reading in the actual experiments. The experiment was repeated in the presence of several electrolytes. Metal ion, its $\mathrm{pH}$ range, buffer used, indicator used and colour change are given in Table 1 . The metal ion uptake can be determined as, Metal ion adsorbed (uptake) by resin $=(X-Y) Z$ meq $/$ gm.

Where,

' $\mathrm{Z}$ ' $\mathrm{ml}$ is the difference between actual experimental reading and blank reading.

' $\mathrm{X}$ ' $\mathrm{mg}$ is metal ion in the $2 \mathrm{ml} 0.1 \mathrm{M}$ metal nitrate solution before uptake.

' $\mathrm{Y}$ ' $\mathrm{mg}$ is metal ion in the $2 \mathrm{ml} 0.1 \mathrm{M}$ metal nitrate solution after uptake.

By using this equation the uptake of various metal ions by resin can be calculated and expressed in terms of milliequivalents per gram of the copolymer.

\section{Estimation of rate of metal ion uptake as function of time}

In order to estimate the time require to reach the state of equilibrium under the given experimental conditions, a series of experiments of the type described above were carried out, in which the metal ion taken up by the chelating resins was determined from time to time at $30^{\circ} \mathrm{C}$ (in the presence of $25 \mathrm{ml}$ of $1 \mathrm{M} \mathrm{NaNO}_{3}$ solution). It was assumed that, under the given conditions, the state of equilibrium was established within $24 \mathrm{hrs}$. The rate of metal uptake is expressed as percentage of the amount of metal ions taken up after a certain time related to that at the state of equilibrium and it can be defined by the following relationship.

\section{The percent amount of metal ions taken up at different time is defined as.}

Percentage of amount of metal ion taken up at different time
Amount of metal ion adsorbed

Amount of metal ion adsorbed at
equilibrium

Percentage of metal ion adsorbed after $1 \mathrm{hr}=(100 \mathrm{X}) / \mathrm{Y}$ 
Where, ' $\mathrm{X}$ ' $\mathrm{mg}$ of metal ion adsorbed after $1 \mathrm{hr}$ and ' $\mathrm{Y}$ ' $\mathrm{mg}$ of metal ion is adsorbed after $25 \mathrm{hrs}$, then by Using this expression, the amount of metal adsorbed by polymer after specific time intervals was calculated and expressed in terms of percentage metal ion adsorbed. This experiment was performed using 0.1M metal nitrate solution of $\mathrm{Fe}^{3+}, \mathrm{Cu}^{2+}, \mathrm{Ni}^{2+}, \mathrm{Co}^{2+}, \mathrm{Zn}^{2+}, \mathrm{Cd}^{2+}$ and $\mathrm{Pb}^{2+}$.

\section{Evaluation of the distribution of metal ions at different pH}

The distribution of each one of the seven metal ions i.e., $\mathrm{Cu}$ (II), $\mathrm{Ni}$ (II), Co (II), $\mathrm{Zn}$ (II), $\mathrm{Cd}$ (II), $\mathrm{Pb}$ (II), and Fe (III) between the polymer phase and the aqueous phase was determined at $30 \square \mathrm{C}$ and in the presence of $1 \mathrm{M} \mathrm{NaNO}_{3}$ solution. The experiments were carried out as described above at different $\mathrm{pH}$ values. The distribution ratio (D) is defined by the following relationship [13].

$$
\mathrm{D}=\frac{\text { Amount of metal ion on resin }}{\text { Amount of metal ion in solution }} \times \frac{\text { Volume of solution }(\mathrm{ml})}{\text { Weight of re } \sin (\mathrm{g})}
$$

Metal ion adsorbed (uptake) by the resin $=\left(\frac{Z X}{Y}\right) \frac{2}{3.025}$

Where,

$Z=$ is the difference between actual experiment reading and blank reading,

$\mathrm{C}=\mathrm{gm}$ is the amount of metal ion in $2 \mathrm{ml} 0.1 \mathrm{M}$ metal nitrate solution,

$\mathrm{Y}=\mathrm{gm}$ is metal ion in $2 \mathrm{ml}$ of metal nitrate solution after uptake. 


\section{Results and Discussion}

The four new copolymer resins 8-HQDF were synthesized by condensing 8-hydroxyquinoline and dithiooxamide with formaldehyde in the presence of $2 \mathrm{M}$ $\mathrm{HCl}$ as catalyst in an oil bath for 5 hours in the molar ratios of $1: 1: 2$. The 8HQDF copolymer resins were found to be green colour. The copolymer resins are soluble in DMF, DMSO and are insoluble in almost all other organic solvents. The melting points of resins were found to be in the range of 118 $130^{\circ} \mathrm{C}$. These resins were analysed for carbon, hydrogen and nitrogen content.

\section{Viscometric Study}

Viscometric measurements were carried out in DMSO solutions at $30^{\circ} \mathrm{C}$ using a Tuan-Fuoss [13] viscometer fabricated in our research laboratory at a different concentrations ranging from 1.00 to $0.031 \%$. Intrinsic viscosity ( $\eta$ ) was calculated from relevant plots of Huggins' equation (1) and Kraemer's equation (2) [14]

$\eta_{\mathrm{sp}} / \mathrm{C}=\eta+\Sigma_{1}[\eta \quad \mathrm{C} \ldots \ldots \ldots \ldots \ldots \ldots \ldots \ldots \ldots \ldots \ldots$

$\ln \eta_{\mathrm{sp}} / \mathrm{C}=\eta-\Sigma_{2}[\eta$

Where, $\mathrm{C}=$ concentration in $\mathrm{gm} / 100 \mathrm{ml}$.

$\eta_{\mathrm{r}}=$ the ratio between viscosity of solution $[\eta]$ and viscosity of the solvent $\left[\eta_{0}\right]$ is known as relative viscosity $\eta_{\mathrm{r}}=\eta / \eta_{0}$

$\eta_{\mathrm{sp}}=$ this function has been derived from relative viscosity and given by

$\eta_{\mathrm{sp}}=\left(\eta_{-} \eta_{0}\right) / \eta_{0}=\eta / \eta_{0}-1=\eta_{\mathrm{r}^{-}}-1$

$[\eta]=$ it is intrinsic viscosity obtained by extrapolating a plot of $\eta_{\mathrm{sp}} / \mathrm{C}$ or $\ln \eta_{\mathrm{r}} / \mathrm{C}$ against concentration. $[\eta]=\lim _{\mathrm{C} \rightarrow}\left(\eta_{\mathrm{sp}} / \mathrm{C}\right)$. The intrinsic viscosity is characteristic parameter of a polymer.

According to above relations, the plots of $\eta_{\mathrm{sp}} / \mathrm{C}$ and $\ln \eta_{\mathrm{r}} / \mathrm{C}$ against concentration were linear with slopes $\mathrm{K}_{1}$ and $\mathrm{K}_{2}$ respectively. Intercepts on the 
viscosity axis give the value of intrinsic viscosity [ $\eta]$ in both the plots. The calculated values of the constant $K_{1}$ and $K_{2}$ in most cases satisfy the relation $\mathrm{K}_{1}+\mathrm{K}_{2}=0.5$ favorably [14]. It was observed that copolymer resins having higher average molecular weight $(\overline{\mathrm{M}} \mathrm{n})$ shows a higher value of intrinsic viscosity $[\eta]$.

\section{Average molecular weight}

The number average molecular weights $(\overline{\mathrm{M}} \mathrm{n})$ of these copolymer resins have been determined by conductometric titration method in non-aqueous medium and using standard potassium hydroxide $(0.05 \mathrm{M})$ in absolute ethanol as a titrant. The results are depicted in Table 3 . The specific conductance was plotted against milliequivalents of ethanolic $\mathrm{KOH}$ required for neutralisation of 100 gm of each copolymer. There are several breaks before the complete neutralisation of all phenolic hydroxyl groups [15]. The first break in the plot was the smallest break and assumed that this corresponds to a stage in titration when an average one phenolic hydroxy group of each chain was neutralised. From the plot, the first and final breaks were recorded. The average degree of polymerization $(\overline{\mathrm{DP}})$ and the number average molecular weight $(\overline{\mathrm{M}} \mathrm{n})$ of all copolymers have been determined given below.

$$
\overline{\mathrm{DP}}=\frac{\text { Total milliequivalents of base for complete neutralisation }}{\text { Milliequivalents of base required for smaller intervals }}
$$

$$
\overline{\mathrm{M}} \mathrm{n}=\overline{\mathrm{DP}} \mathrm{x} \text { Repeat unit weight }
$$

It is observed that the molecular weight of copolymers increase with increase in 8-hydroxiquiniline content. This observation is in agreement with the trend observed by earlier workers [16].

\section{Electronic Spectra}

The electronic spectra of the 8-HQDF terpolymer resins give rise to a similar pattern and are depicted in Figure 3. The spectra of these terpolymers exhibit two absorption maxima in the region 260 to $290 \mathrm{~nm}$ and 315 to $330 \mathrm{~nm}$. 
The intense band at $270 \mathrm{~nm}$ is due to $(\pi-\pi *)$ allowed transition of quinoline moiety which readily attains coplanarity and the shoulders merging (loss of fine structure) band at $324 \mathrm{~nm}$ may be due to $(\mathrm{n}-\pi *)$ forbidden transition in saturated aliphatic carbonyl compounds [17]. The bathocromic shift from the basic values viz. $260 \mathrm{~nm}$ and $270 \mathrm{~nm}$ respectively may be due to combined effect of conjugation and phenolic hydroxy group (auxochrome) [17].

\section{Infrared Spectra}

The IR spectra of terpolymer resins are presented in Figure 4 and IR spectral data are incorporated in Table III. The IR spectra revealed that all these resins give rise to a nearly similar pattern of spectra. A broad band appearing in the region $3400-3800 \mathrm{~cm}^{-1}$ may be assigned to the stretching vibration of phenolic hydroxy groups exhibiting intermolecular hydrogen bonding with the thionyl group of a different polymeric chain i.e. $-\mathrm{OH}$ phenolic intermolecular polymeric association[18]. The band at $1750-1600 \mathrm{~cm}^{-1}$ may be due to the stretching vibrations of $>\mathrm{C}=\mathrm{S}$ group of amide moiety [18]. The band at 2900 $\mathrm{cm}^{-1}$ assignable to $-\mathrm{NH}$ - stretching, bending and deformation out of plane vibrations of dithiooxamide moiety in terpolymers respectively. The band at $1502 \mathrm{~cm}^{-1}$ may be ascribed to aromatic skeletal ring [18]. The presence of methylene bridges $\left(-\mathrm{CH}_{2}-\right)$ in the polymeric chain may be assigned due to presence of band at $1460-1470 \mathrm{~cm}^{-1}, 1375-1360 \mathrm{~cm}^{-1}$ and $788-753 \mathrm{~cm}^{-1}\left[-\mathrm{CH}_{2}^{-}\right.$ rocking] [18]. The band obtained at $1009 \mathrm{~cm}^{-1}, 1111 \mathrm{~cm}^{-1}$ and $1161 \mathrm{~cm}^{-1}$ suggest that the aromatic ring is $3,4,8$ substituted.

\section{Nuclear Magnetic Resonance Spectra}

Proton NMR spectra of terpolymer resins are presented in Figure 5. NMR spectral data are shown in Table IV. Proton NMR spectra of all terpolymer resins show the intense signal arising in the region 8.12 to $8.20(\delta)$ ppm which may occur on account of hydroxyl proton of phenolic -OH group involved in the intermolecular hydrogen bonding[19]. The sharp intense peak at 6.10 to $6.80(\delta)$ ppm may be assigned to aromatic proton. A weak signal made its appearance at 4.16 to $4.46(\delta)$ ppm which may be due to amido protons of $-\mathrm{NH}$ bridge in the

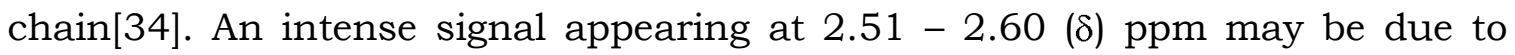


methylene proton of Ar- $\mathrm{CH}_{2}-\mathrm{Ar}$ moiety. Except 8-HQDF-1 terpolymer, the remaining three terpolymer which are 8-HQDF-2, 8-HQDF-3 and 8-HQDF-4 show signal around $3.62(\delta)$ ppm suggesting the presence of methylene bridges of $\mathrm{Ar}-\mathrm{CH}_{2}-\mathrm{N}$ linkage[19].

On the basis of the nature and reactive position of the monomers, elemental analysis UV-visible, IR, NMR spectral studies and taking into consideration the linear structure of other phenol -formaldehyde and the linear branched nature of urea-formaldehyde polymers, the most probable structure has been proposed for 8-HQDF copolymer resin, has been shown in Fig. 1. The morphology of the resin shows the transition between crystalline and amorphous nature, when compare to the other resin, the 8-HQDF copolymer resin is more amorphous in nature, hence, higher metal ion exchange capacity.

\section{Ion-exchange properties}

Batch equilibrium technique developed by Gregor et al and De Geiso et al was used to study ion exchange properties of 8-HQDF copolymer resin. The results of the batch equilibrium study carried out with the copolymer 8-HQDF are presented in Table 5, 6 and 7. Seven metal ions $\mathrm{Fe}^{3+}, \mathrm{Cu}^{2+}, \mathrm{Ni}^{2+}, \mathrm{Co}^{2+}, \mathrm{Zn}^{2+}$, $\mathrm{Cd}^{2+}$ and $\mathrm{Pb}^{2+}$ in the form of aqueous metal nitrate solution were used. The ion exchange study was carried out using three experimental variables: a) Electrolyte and its ionic strength b) uptake time and c) $\mathrm{pH}$ of the aqueous medium. Among these three variables, two were kept constant and only one was varied at a time to evaluate its effect on metal uptake capacity of the polymers, similar to the earlier co-workers [19]. The details of experimental procedure are given below.

\section{Effect of electrolyte and its ionic strength on metal uptake}

We examined the influence of $\mathrm{CIO}_{4}^{-}, \mathrm{NO}_{3}^{-}$, CI- and $\mathrm{SO}_{4}{ }^{2-}$ at various concentrations on the equilibrium of metal-resin interaction. Table 5 shows that the amount of metal ions taken up by a given amount of copolymer depends on the nature and concentration of the electrolyte present in the solution. Generally as concentration of the electrolyte increases, the ionization decreases, by the number of ligands (negative ions of electrolyte) decrease in the solution 
which forms the complex with less number of metal ions and therefore more number of ions may available for adsorption. Hence on increasing concentration, uptake of metal ions may be increased, which is the normal trend. But this normal trend disturbed due to the formation of stable complex with more number of metal ions with electrolyte ligands, which decrease the number of metal ions available for adsorption, hence uptake decreases. In the presence of perchlorate, chloride and nitrate ions, the uptake of $\mathrm{Fe}$ (III), $\mathrm{Cu}$ (II) and $\mathrm{Ni}$ (II) ions increase with increasing concentration of the electrolytes, whereas in the presence of sulphate ions the amount of the above mentioned ions taken up by the copolymer decreases with increasing concentration of the electrolyte [20]. Moreover, the uptake of Co (II), $\mathrm{Zn}$ (II), Cd (II) and Pb (II) ions increase with decreasing concentration of the chloride, nitrate, perchlorate and sulphate ions. This may be explained on the basis of the stability constants of the complexes with those metal ions [36]. The ratio of physical core structure of the resin is significant in the uptake of different metal ions by the resin polymer. The amount of metal ion uptake by the 8-HQDF copolymer resin is found to be higher when comparing to the other polymeric resins [20].

\section{Estimation of the rate of metal ion uptake as a function of time}

The rate of metal uptake was determined to find out the shortest period of time for which equilibrium could be carried while operating as close to equilibrium conditions as possible. As shaking time increases the polymer gets more time for adsorption, hence uptake increases. Table 6 shows the dependence of the rate of metal ion uptake on the nature of the metal. The rate refers to the change in the concentration of the metal ions in the aqueous solution which is in contact with the given polymer. The result shows that the time taken for the uptake of the different mental ions at a given stage depends on the nature of the metal ion under given conditions. It is found that Fe (III) ions require about $3 \mathrm{hrs}$ for the establishment of the equilibrium, whereas $\mathrm{Cu}$ (II), Ni (II), Co (II) and Zn (II) ions required about 5 or 6 hrs [21]. Thus the rate of metal ions uptake follows the order $\mathrm{Cu}$ (II) $>\mathrm{Ni}$ (II) $>\mathrm{Co}$ (II) $\approx \mathrm{Zn}$ (II) $>\mathrm{Cd}$ (II) $>$ $\mathrm{Pb}$ (II) for all of the copolymers [21]. The rate of metal uptake may depend upon 
hydrated radii of metal ions. The rate of uptake for the post transition metal ions such as Cd (II) exhibits other trend, the rate of uptake is in the comparable that of $\mathrm{Pb}$ (II) because of difference in'd' orbital.

\section{Distribution ratios of metal ions at different $\mathrm{pH}$}

The distributions of metal ion depend upon $\mathrm{pH}$ of the solution. As $\mathrm{pH}$ of the solution increases, the $\mathrm{H}^{+}$ion concentration of the solution decrease. More number of metal ions in the solution available for adsorption which increase uptake.

The effect of $\mathrm{pH}$ on the amount of metal ions distributed between two phases can be explained by the data given in Table 7 and Figure 11. The data on the distribution ratio as a function of $\mathrm{pH}$ indicate that the relative amount of metal ion taken up by the 8-HQDF copolymer increases with increasing $\mathrm{pH}$ of the medium [22].The magnitude of increase, however, is different for different metal cations. The study was carried from $\mathrm{pH} 2.5$ to 6.5 to prevent hydrolysis of metal ions at higher $\mathrm{pH}$. For metal ion $\mathrm{Fe}^{3+}$ the highest working $\mathrm{pH}$ is 3 , where distribution ratio is medium, since $\mathrm{Fe}^{3+}$ forms octahedral complex with electrolyte ligand, showing crowding effect (sterric hindrance), which may lower the distribution ratio of $\mathrm{Fe}^{3+}$ ions. The value of distribution ratio at particular $\mathrm{pH}$ thus depends upon the nature and stability of chelates with particular metal ion. The data of distribution ratio show a random trend in certain cases [22]. This may be due to the amphoteric nature of the 8-HQDF resin. From the result it reveals that with decrease in atomic number, the ion uptake capacity is increased. In case of $\mathrm{Cd}$ (II) and $\mathrm{Pb}$ (II) purely electrostatic factors are responsible. The ion uptake capacity of $\mathrm{Cd}$ (II) is lower owing to the large size of its hydrated ion than that of $\mathrm{Cu}$ (II). The sterric influence of the methyl group and hydroxyl group in 8-HQDF resin is probably responsible for their observed low binding capacities for various metal ions. Thus the interaction of this resin material with various metal ions in an aqueous environment may largely limit the binding sites, which are suitably, disposed in a conformationals favourable manner on the surface layer. The higher value of distribution ratio for $\mathrm{Cu}$ (II) and $\mathrm{Ni}$ (II) at $\mathrm{pH} 4$ to 6.0 may be due to the formation of more stable complex with chelating ligands. Therefore the polymer under study has more selectivity 
of $\mathrm{Cu}^{2+}$ and $\mathrm{Ni}^{2+}$ ions at $\mathrm{pH} 4.0$ to 6.0 then other ions which form rather weak complex. While at pH 3 the copolymer has more selectivity of $\mathrm{Fe}^{3+}$ ions. The 8HQDF copolymer resin takes up Fe(III) ion more selectively. The order of distribution ratio of metal ions measured in $\mathrm{pH}$ range 2.5 to 6.5 is found to be $\mathrm{Fe}$ (III) $>\mathrm{Cu}$ (II) $>\mathrm{Ni}$ (II) $>\mathrm{Zn}$ (II) $>\mathrm{Co}$ (II) $>\mathrm{Pb}$ (II) $>\mathrm{Cd}$ (II). Thus the results of such type of study are helpful in selecting the optimum $\mathrm{pH}$ for a selective uptake of a particular metal cation from a mixture of different metal ions [40]. For example, the result suggests the optimum $\mathrm{pH} 6.0$, for the separation of $\mathrm{Co}(\mathrm{II})$ and $\mathrm{Ni}$ (II) with distribution ratio ' $\mathrm{D}$ ' at 359.7 and 782.5 respectively using the 8-HQDF copolymer resin as ion-exchanger. Similarly, for the separation of $\mathrm{Cu}$ (II) and $\mathrm{Fe}$ (III) the optimum $\mathrm{pH}$ is 3, at which the distribution ratio ' $\mathrm{D}$ ' for $\mathrm{Cu}$ (II) is 54.9 and that for Fe (III) are 382.6. The lowering in the distribution of Fe (III) was found to be small and, hence, efficient separation could be achieved [22-23].

Ion exchange properties of various resins can be studied by comparing their ion exchange capacity. The ion exchange capacity (IEC) is a fundamental and important quantity for the characterization of any ion exchange material. It is defined as the amount of ion that undergoes exchange in a definite amount of material, under specified experimental conditions. However, there may be complication in the determination of the capacity The ion exchange capacity of 8-HQDF copolymer has been calculated, which indicates that 8-HQDF copolymer resin is better ion exchanger than commercial phenolic and some polystyrene commercial ion exchangers. 
Table 1

Evaluation of the effect of different electrolytes on the uptake of several metal ions ${ }^{a}$ by 8-HQDF terpolymer resin

\begin{tabular}{|c|c|c|c|c|c|c|}
\hline \multirow{2}{*}{ Metal ion } & \multirow{2}{*}{$\begin{array}{l}\text { Electrolyte } \\
\quad(\mathrm{mol} / 1)\end{array}$} & \multirow{2}{*}{$\mathrm{pH}$} & \multicolumn{4}{|c|}{$\begin{array}{l}\text { Weight of the metal uptake (meq. } \mathrm{g}^{-1} \text { ) } \\
\text { in the presence of }\end{array}$} \\
\hline & & & $\mathrm{NaNO}_{3}$ & $\mathrm{NaCl}$ & $\mathrm{NaClO}_{4}$ & $\mathrm{Na}_{2} \mathrm{SO}_{4}$ \\
\hline \multirow{6}{*}{$\mathrm{Fe}(\mathrm{III})$} & 0.01 & \multirow{5}{*}{2.5} & 0.97 & 1.29 & 1.24 & 1.84 \\
\hline & 0.05 & & 1.64 & 1.42 & 1.40 & 1.79 \\
\hline & 0.10 & & 2.52 & 1.72 & 1.72 & 1.67 \\
\hline & 0.50 & & 2.71 & 2.31 & 2.35 & 1.59 \\
\hline & 1.00 & & 3.21 & 2.39 & 3.06 & 0.86 \\
\hline & 0.01 & \multirow{5}{*}{4.5} & 2.29 & 2.13 & 2.24 & 3.42 \\
\hline \multirow{5}{*}{$\mathrm{Cu}(\mathrm{II})$} & 0.05 & & 2.94 & 2.62 & 2.31 & 2.84 \\
\hline & 0.10 & & 3.32 & 2.79 & 2.69 & 2.53 \\
\hline & 0.50 & & 3.49 & 3.06 & 3.02 & 1.80 \\
\hline & 1.00 & & 3.60 & 3.29 & 3.27 & 0.95 \\
\hline & 0.01 & \multirow{5}{*}{4.5} & 1.22 & 1.35 & 1.42 & 2.82 \\
\hline \multirow{4}{*}{$\mathrm{Ni}(\mathrm{II})$} & 0.05 & & 1.28 & 1.72 & 1.69 & 2.95 \\
\hline & 0.10 & & 1.35 & 2.15 & 2.56 & 1.86 \\
\hline & 0.50 & & 1.72 & 2.27 & 2.65 & 1.75 \\
\hline & 1.00 & & 1.89 & 2.61 & 3.26 & 1.62 \\
\hline \multirow{6}{*}{$\mathrm{Co}(\mathrm{II})$} & 0.01 & \multirow{6}{*}{5.00} & 1.79 & 1.84 & 1.65 & 1.72 \\
\hline & 0.05 & & 1.63 & 1.72 & 1.58 & 1.63 \\
\hline & 0.10 & & 1.26 & 1.59 & 1.36 & 1.59 \\
\hline & 0.50 & & 0.95 & 1.26 & 0.91 & 0.94 \\
\hline & 1.00 & & 0.78 & 0.84 & 0.75 & 0.86 \\
\hline & 0.01 & & 1.79 & 2.45 & 1.99 & 2.19 \\
\hline \multirow{4}{*}{$\mathrm{Zn}(\mathrm{II})$} & 0.05 & \multirow{4}{*}{5.00} & 1.64 & 2.32 & 1.87 & 1.92 \\
\hline & 0.10 & & 1.28 & 1.94 & 1.45 & 1.73 \\
\hline & 0.50 & & 0.96 & 1.25 & 1.27 & 1.52 \\
\hline & 1.00 & & 0.77 & 0.86 & 0.94 & 0.89 \\
\hline \multirow{6}{*}{$\mathrm{Cd}(\mathrm{II})$} & 0.01 & \multirow{5}{*}{5.00} & 1.82 & 2.39 & 1.85 & 1.59 \\
\hline & 0.05 & & 1.59 & 2.26 & 1.72 & 1.37 \\
\hline & 0.10 & & 1.36 & 1.19 & 1.68 & 1.22 \\
\hline & 0.50 & & 1.28 & 1.02 & 1.39 & 1.15 \\
\hline & 1.00 & & 0.96 & 0.91 & 1.27 & 0.97 \\
\hline & 0.01 & \multirow{5}{*}{6.00} & 1.86 & 1.94 & 1.72 & 1.82 \\
\hline \multirow{4}{*}{$\mathrm{Pb}(\mathrm{II})$} & 0.05 & & 1.42 & 1.75 & 1.54 & 1.74 \\
\hline & 0.10 & & 1.27 & 1.46 & 1.35 & 1.54 \\
\hline & 0.50 & & 0.95 & 1.32 & 1.15 & 1.15 \\
\hline & 1.00 & & 0.79 & 0.85 & 0.82 & 0.96 \\
\hline
\end{tabular}

$\mathrm{a}\left[\mathrm{M}\left(\mathrm{NO}_{3}\right)_{2}\right]=0.1 \mathrm{~mol} / 1 ;$ Volume $=2 \mathrm{ml} ;$ Volume of electrolyte solution : $25 \mathrm{ml}$

Weight of resin $=25 \mathrm{mg}$; time $: 24 \mathrm{~h}:$ Room temperature. 
Table 2

Comparison of th 8-HQDF terpolymer resin

\begin{tabular}{|c|c|c|c|c|c|c|c|}
\hline \multirow{2}{*}{$\begin{array}{c}\text { Metal } \\
\text { ion }\end{array}$} & \multirow{2}{*}{ pH } & \multicolumn{6}{|c|}{$\begin{array}{c}\text { Percentage of metal ion uptake }{ }^{\mathrm{b}} \text { at } \\
\text { different times (h) }\end{array}$} \\
\cline { 3 - 8 } & & 1 & 2 & 3 & 4 & 5 & 6 \\
\hline $\mathrm{Fe}(\mathrm{III})$ & $\mathbf{2 . 5}$ & 72.9 & 85.7 & 95.7 & - & - & - \\
$\mathrm{Cu}(\mathrm{II})$ & $\mathbf{4 . 5}$ & 69.6 & 75.6 & 79.2 & 85.9 & 94.6 & - \\
$\mathrm{Ni}(\mathrm{II})$ & $\mathbf{4 . 5}$ & 63.4 & 74.6 & 82.7 & 87.3 & 98.4 & - \\
$\mathrm{Co}(\mathrm{II})$ & $\mathbf{5}$ & 48.5 & 62.7 & 72.8 & 85.6 & 95.8 & - \\
$\mathrm{Zn}(\mathrm{II})$ & $\mathbf{5}$ & 53.7 & 64.9 & 69.5 & 85.9 & 98.5 & - \\
$\mathrm{Cd}(\mathrm{II})$ & $\mathbf{5}$ & 36.5 & 54.2 & 64.9 & 75.6 & 86.9 & 79.8 \\
$\mathrm{~Pb}(\mathrm{II})$ & $\mathbf{6}$ & 38.9 & 52.5 & 62.7 & 74.9 & 82.8 & 96.7 \\
\hline
\end{tabular}

a $\left[\mathrm{M}\left(\mathrm{NO}_{3}\right)_{2}\right]=0.1 \mathrm{~mol} / 1$; volume : $2 \mathrm{ml} ; \mathrm{NaNO}_{3}=1.0 \mathrm{~mol} / \mathrm{L}$; volume: $25 \mathrm{ml}$, Room temperature.

b Metal ion uptake $=($ Amount of metal ion absorbed $\mathrm{x} 100) /$ amount of metal ion absorbed at

equilibrium.

\section{Table 3}

\section{Distribution ratio $D^{a}$ of various metal ions ${ }^{b}$ as function of}

\section{the pH by 8-HQDF terpolymer resin}

\begin{tabular}{|l|c|c|c|c|c|c|c|c|}
\hline \multirow{2}{*}{$\begin{array}{c}\text { Metal } \\
\text { ion }\end{array}$} & \multicolumn{7}{|c|}{ Distribution ratio of the metal ion at different $\mathrm{pH}$} \\
\cline { 2 - 9 } & 1.5 & 2 & 2.5 & 3 & 3.5 & 4 & 5 & 6 \\
\hline $\mathrm{Fe}(\mathrm{III})$ & 2.67 & 182.5 & 264.3 & 382.6 & - & - & - & - \\
$\mathrm{Cu}(\mathrm{II})$ & - & - & - & 54.9 & 72.9 & 178.4 & 679.5 & 948.7 \\
$\mathrm{Ni}(\mathrm{II})$ & - & - & - & 46.7 & 64.9 & 182.7 & 362.9 & 782.5 \\
$\mathrm{Co}(\mathrm{II})$ & - & - & - & 29.7 & 59.2 & 109.7 & 228.5 & 359.7 \\
$\mathrm{Zn}(\mathrm{II})$ & - & - & - & 37.5 & 66.7 & 102.9 & 167.4 & 258.5 \\
$\mathrm{Cd}(\mathrm{II})$ & - & - & - & 27.4 & 42.8 & 77.5 & 158.4 & 229.5 \\
$\mathrm{~Pb}(\mathrm{II})$ & - & - & - & 39.6 & 68.5 & 117.5 & 162.8 & 232.5 \\
\hline
\end{tabular}


a $\mathrm{D}=$ weight (in $\mathrm{mg}$ ) of metal ions taken up by $1 \mathrm{~g}$ of copolymer/weight (in $\mathrm{mg}$ ) of metal ions present in $1 \mathrm{ml}$ of solution.

b $\left[\mathrm{M}\left(\mathrm{NO}_{3}\right)_{2}\right]=0.1 \mathrm{~mol} / 1$; volume : $2 \mathrm{ml} ; \mathrm{NaNO}_{3}=1.0 \mathrm{~mol} / 1$; volume: $25 \mathrm{ml}$, time 24h (equilibrium state) at Room temperature.

\section{CONCLUSION}

A copolymer 8-HQDF based on the condensation reaction of 8hydroxyquinoline dithiooxamide with formaldehyde in the presence of acid catalyst was prepared. 8-HQDF is a selective chelating ion-exchange copolymer resin for certain metal ions. The copolymer resin showed a higher selectivity for $\mathrm{Fe}^{3+}, \mathrm{Cu}^{2+}$ and $\mathrm{Ni}^{2+}$ ions than for $\mathrm{Co}^{2+}, \mathrm{Zn}^{2+}, \mathrm{Cd}^{2+}$ and $\mathrm{Pb}^{2+}$ ions. The uptake of some metal ions by the resin was carried out by the batch equilibrium technique. The uptake capacities of metal ions by the copolymer resin were $\mathrm{pH}$ dependent. From the results of distribution coefficients, it can be observed that $\mathrm{Cu}$ (II) has higher value of distribution ratio. Due to considerable difference in the uptake capacities at different $\mathrm{pH}$ and media of electrolyte, the rate of metal ion uptake and distribution ratios at equilibrium, it is possible to use for separation of particular metal ions from their admixture.

\section{ACKNOWLEDGEMENT}

The authors are pleased to express their gratitude to the University Grant Commission, New Delhi for financial assistance

\section{REFERENCES}

Prabhakar L.D., Umarani C., (1994) J. Polym. Mater., 11, 147-156.

Devi S., Shah A., , (1987) Talanta, 34, 547-550.

Lee W., Lee S.E., Kim M.Y., (2002) Bull. Korean Chem. Soc., 23, 1067-1072.

DeGeiso R.C., Donaruma L., Tomic (1962) E., , Anal. Chem., 34, 845-847.

Patel M., Manavalan R., (1983) Indian J. Chem., 22A, 117-119.

Patel M.M., Manavalan R., (1984) J. Indian Chem. Soc., 61, 490- 494.

Vyas M.V., Kapadia R.N., (1980) Indian J. Technol., 18, 411-415. 
Vyas M.V., Kapadia R.N., (1981) Indian J. Technol., 19, 491-49.

Amin S., Kapadia R.N., (1997) J. Sci. Ind. Res., 56, 540-544.

Shah BA, Shah AV, Bhandari BN, (2001) Asia J hem, 13, 1305-1308.

Jadhao M M, Paliwal L J, Bhave N S, (2005) J App Polym Sci, 96, 1606-1610.

Gupta R H, Zade A B, Gurnule WB, (2008) J. Appl. Polym, 109, 3315-3320.

Patel S A, Shah B S, Patel R M, Patel P M, (2004) Iran Polym J, 13, 445-453,.

Shah A B, Shah A V, Shah M P, (2006) Iran Polym J, 15, 809-819.

Michael P. E. P., Lingala P. S., Juneja H. D., Paliwal L. J., (2004) J. Appl. Polym. Sci., 92(4) 2278-2283.

Gurnule W. B., Juneja H. D., Paliwal L. (2003) J., Ultra Science, 15(1), 135-142.

Jadhao M. M., Paliwal L. J., Bhave N. S., (2005) J. of Appl. Poly. Sci., 96(5) 1605-1610.

Gurnule W. B., Rahandale P. K., Paliwal L. J., Kharat R. B., (2002) Prog. Cryst. Grow. Charact. Mat., 45, 155-160.

Jadhao M. M., Paliwal L. J., Bhave N. S., (2008) J. of App. Poly. Sci., 109(1), 508-514.

Patel S. A., Shah B. S., Patel R. M., Patel P. M., (2004) Indian Poly. Journal, 13(6), 445-453.

Gurnule W. B., Juneja H. D., Paliwal L. J., (2000) Asian J. Chem., 12(1), 51 57.

Lingala P. S., Paliwal L. J., Juneja H. D., (2001) Proc. Nat. Acad. Sci. India, $71(\mathrm{~A}), 205-212$.

Pal T. K., Kharat R. B., Die, (1989) Angew. Makromol. Chem., 173, 55-68. 